\title{
Semiochemicals from Herbivory Induced Cotton Plants Enhance the Foraging Behavior of the Cotton Boll Weevil, Anthonomus grandis
}

\author{
D. M. Magalhães • M. Borges • R. A. Laumann • E. R. Sujii • P. Mayon • \\ J. C. Caulfield • C. A. O. Midega • Z. R. Khan • J. A. Pickett • \\ M. A. Birkett • M. C. Blassioli-Moraes
}

Received: 7 August 2012 /Revised: 11 October 2012 / Accepted: 1 November 2012 /Published online: 21 November 2012

(C) Springer Science+Business Media New York 2012

\begin{abstract}
The boll weevil, Anthonomus grandis, has been monitored through deployment of traps baited with aggregation pheromone components. However, field studies have shown that the number of insects caught in these traps is significantly reduced during cotton squaring, suggesting that volatiles produced by plants at this phenological stage may be involved in attraction. Here, we evaluated the chemical profile of volatile organic compounds (VOCs) emitted by undamaged or damaged cotton plants at different phenological stages, under different infestation conditions, and determined the attractiveness of these VOCs to adults of $A$. grandis. In addition, we investigated whether or not VOCs released by cotton plants enhanced the attractiveness of the aggregation pheromone emitted by male boll weevils. Behavioral responses of $A$.
\end{abstract}

D. M. Magalhães • M. Borges • R. A. Laumann • E. R. Sujii •

M. C. Blassioli-Moraes

Embrapa Genetic Resources and Biotechnology,

W5 Norte,

CEP 70770-900, Brasília, DF, Brazil

D. M. Magalhães $\cdot$ E. R. Sujii

Ecology Department, University of Brasília (UnB),

Brasília, Brazil

P. Mayon - J. C. Caulfield - J. A. Pickett - M. A. Birkett

Biological Chemistry and Crop Protection Department,

Rothamsted Research,

Harpenden, UK

\section{A. O. Midega $\cdot$ Z. R. Khan}

International Centre of Insect Physiology and Ecology (icipe),

Mbita Point, Kenya

M. C. Blassioli-Moraes $(\square)$

Embrapa Recursos Genéticos e Biotecnologia—Parque Estação

Biológica,

W5 Norte,

CEP 70770-900, Brasília, DF, Brazil

e-mail: carolina.blassioli@embrapa.br grandis to VOCs from conspecific-damaged, heterospecificdamaged (Spodoptera frugiperda and Euschistus heros) and undamaged cotton plants, at different phenological stages, were assessed in Y-tube olfactometers. The results showed that volatiles emitted from reproductive cotton plants damaged by conspecifics were attractive to adults boll weevils, whereas volatiles induced by heterospecific herbivores were not as attractive. Additionally, addition of boll weevil-induced volatiles from reproductive cotton plants to aggregation pheromone gave increased attraction, relative to the pheromone alone. The VOC profiles of undamaged and mechanically damaged cotton plants, in both phenological stages, were not different. Chemical analysis showed that cotton plants produced qualitatively similar volatile profiles regardless of damage type, but the quantities produced differed according to the plant's phenological stage and the herbivore species. Notably, vegetative cotton plants released higher amounts of VOCs compared to reproductive plants. At both stages, the highest rate of VOC release was observed in A. grandis-damaged plants. Results show that $A$. grandis uses conspecific herbivore-induced volatiles in host location, and that homoterpene compounds, such as $(E)$-4,8-dimethylnona-1,3,7-triene and $(E, E)$-4,8,12-trimethyltrideca-1,3,7,11-tetraene and the monoterpene $(E)$-ocimene, may be involved in preference for host plants at the reproductive stage.

Keywords Host plant · Herbivore-induced plant volatiles . Phenological stages · Terpenoids · Coleoptera .

Curculionidae

\section{Introduction}

Plants respond to insect herbivory through increased local and systemic emission of volatile organic compounds (VOCs) (Paré and Tumlinson, 1996, 1998). The composition 
of the VOCs emitted by herbivore-damaged plants depends on plant species, variety, and phenological stage, as well as the type of herbivore (Turlings et al., 1993; Hare, 2011; Michereff et al., 2011). Induced volatiles are used by herbivores either to find conspecifics or to detect the presence of competitors in the local environment, i.e., to avoid herbivore-damaged plants (Loughrin et al., 1996; Kalberer et al., 2001; Meiners et al., 2005). Herbivores that exploit this volatile output reduce their foraging time, thereby minimizing search cost and exposure to mortality factors (Stamps and Krishnan, 2005).

Within the subfamily Anthonominae (Curculionidae), the pepper weevil, Anthonomus eugenii Cano, the cranberry weevil, A. musculus Cano, the strawberry blossom weevil, A. rubi Herbst, and the apple blossom weevil, A. pomorum L., respond to constitutive and induced host plant VOCs (Kalinova et al., 2000; Bichão et al., 2005; Addesso and McAuslane, 2009; Szendrei et al., 2009; Addesso et al., 2011). Although the attraction of the boll weevil, Anthonomus grandis Boheman, to volatiles released by cotton, Gossypium hirsutum L., has been described previously, the influence of herbivore-induced cotton volatiles has yet to be fully elucidated. Previous studies by Dickens $(1984,1989)$ and Dickens et al. (1990), using Y-tube olfactometry and electrophysiological assays, showed that adult $A$. grandis were attracted to green leaf volatiles from cotton plants. Earlier, McKibben et al. (1977), in field experiments, provided evidence that A. grandis responded to constitutively produced cotton volatiles.

Anthonomus grandis is the major pest in cotton crops in Brazil. Feeding and oviposition by $A$. grandis causes abscission of cotton squares and bolls, leading to substantial overall losses in production and reduction in fiber quality (Beltrão and Azevedo, 2008). Overwintering A. grandis stay in sheltered areas surrounding cotton fields and feed on pollen, mainly from plants in the Smilacaceae (Ribeiro et al., 2010). Cotton plants play a role in the attraction of the first weevils that arrive in a field. The migration of weevils from natural refuges to cotton fields starts with squaring cotton (White and Rummel, 1978; Rummel and Curry, 1986), suggesting that $A$. grandis may use specific VOCs, or blends, during migration.

Anthonomus grandis produces and releases its aggregation pheromone after feeding on cotton squares (Tumlinson et al., 1969), with cotton VOCs synergizing pheromone activity (Dickens, 1989; Dickens et al., 1990). To investigate the hypothesis that $A$. grandis-induced VOCs from cotton plants provide $A$. grandis with information on the location of host plants, we examined the behavioral responses of adults to volatiles from undamaged, conspecific-damaged, and heterospecific-damaged cotton plants, at both vegetative and reproductive stages.

\section{Methods and Materials}

Insects

Anthonomus grandis were from a laboratory colony maintained at Embrapa Genetic Resources and Biotechnology in Brasília, DF, Brazil. Weevils were reared in plastic containers on artificial diet [a mixture of agar, beer yeast, wheat germ, soy protein, glucose, ascorbic and sorbic acid, Nipagin, flour from embryo of cottonseed (Pharmamedia ${ }^{\circledR}$, Traders Protein, USA), Wesson salt mixture, Vanderzant's vitamin, and water; Schmidt et al., 2001], and maintained at $25 \pm 1{ }^{\circ} \mathrm{C}$ and $60 \pm 10 \%$ r. h., under a photoperiod of 14 1: 10D. Newly molted adults were sexed, transferred to $250 \mathrm{ml}$ plastic cages (10 insects/cage), and fed with fresh excised cotton squares and water, three times per week. To prevent interactions between sexes, males were kept in separate cages from females after the imaginal molt. Virgin male and female boll weevils were used in all experiments. Neotropical brown stinkbugs, Euschistus heros Fabricius, were from a laboratory colony maintained at Embrapa Genetic Resources and Biotechnology in Brasília, DF, Brazil. The bugs were reared in plastic containers, as described by Borges et al. (2006), on a diet of soybean, Glycine max L., sunflower seeds, Helianthus annuus L., raw peanuts, Arachis hypogaea L., fresh green beans, Phaseolus vulgaris L., and water. The food supply was renewed twice a week. To obtain virgin females for the experiments, insects were sexed after the imaginal molt and cuticular hardening, and thereafter maintained separately from males. Spodoptera frugiperda (Smith) larvae were obtained from a laboratory colony maintained at Embrapa Genetic Resources and Biotechnology in Brasília, DF, Brazil. They were reared in plastic containers, on an artificial diet based on beans (P. vulgaris), and maintained at $26 \pm 1{ }^{\circ} \mathrm{C}$ and $65 \pm 10 \% \mathrm{r}$. h. under a photoperiod of 14 1: 10D. The larvae were used in experiments when they had reached third instar (Schmidt et al., 2001).

\section{Plant Material}

Gossypium hirsutum seeds (var. Delta Opal) were germinated on damp filter paper. When the cotyledons started expanding, they were transplanted to plastic pots filled with a mixture of soil and organic substrate (in a proportion of 1:1), and placed in a greenhouse at 14 1: $10 \mathrm{D}$ and $27 \pm 1{ }^{\circ} \mathrm{C}$. Plants were watered as needed. All plants used in experiments were 6 weeks old at the vegetative stage (up to 6 expanded true leaves and about $30 \mathrm{~cm}$ high) or 12 weeks old at the reproductive stage (presence of the first cotton square bud and about $50 \mathrm{~cm}$ high).

Boll Weevil Aggregation Pheromone

Small pieces ( $0.05 \mathrm{~g}$ mean weight) of boll weevil aggregation pheromone (Luretape BW-10, Biocontole Métodos de Controle 
de Pragas Ltda., Emigsville, PA, USA), corresponding to $0.751 \mathrm{mg}$ of the four components of the aggregation pheromone in a commercial formulation [0.35:0.43:0.13:0.09 of (Z)-2-isopropenyl-1-methylcyclobutaneethanol, (Z)-2-(3,3-dimethyl)cyclohexylideneethanol, (Z)-(3,3-dimethyl)-cyclohexylideneacetaldehyde and (E)-(3,3-dimethyl)-cyclohexylideneacetaldehyde], were used in experiments.

\section{Olfactometer Bioassays}

The behavioral responses of male and female $A$. grandis to cotton plant VOCs were investigated in a Y-tube olfactometer. A square acrylic block $(26.0 \times 23.0 \mathrm{~cm})$, with a Yshaped cavity $(1.5 \mathrm{~cm}$ thickness) sandwiched between two glass plates, was used as the bioassay arena. The trunk of the apparatus was $12.0 \mathrm{~cm}$, with each arm $10.5 \mathrm{~cm}$ (Moraes et al., 2005). Filter papers containing the extracts obtained from the volatile collections were placed in glass syringes connected to the olfactometer arms via silicon tubing. Charcoal-filtered and humidified air was pushed into the system at $0.61 . \mathrm{min}^{-1}$ and pulled out at $0.21 . \mathrm{min}^{-1}$. This 'push-pull' system prevented entry of contaminating volatiles from the exterior. The bioassays were carried out in a controlled environment room at $25 \pm 1{ }^{\circ} \mathrm{C}$ and $60 \pm 10 \% \mathrm{r}$. h., on a white bench under artificial lighting (514 lx). A male or female boll weevil was introduced, individually, at the base of the trunk of the Y-tube olfactometer, and observed for $10 \mathrm{~min}$. The first choice of an arm was noted. If no choice was made within $5 \mathrm{~min}$, the assay was concluded, and the insect was recorded as non-responding (Borges et al., 2007). The first choice was considered to be when a weevil entered $3.0 \mathrm{~cm}$ into an arm and remained there for at least $20 \mathrm{sec}$. Residence time (the time spent in an arm) was also recorded. Both sexes were assayed simultaneously in two olfactometers, until a total of 60 males and 60 females had responded. Each individual was used only once, and the filter papers replaced after five repetitions. After five replications, the Ytube olfactometer was exchanged for a clean one, and the side on which the treatment was presented was swapped to avoid any positional bias. Treatment types were also changed after every five replications. Glass materials were cleaned with detergent, distilled water, and acetone prior to use. Silicone tubing, filter papers, and glass syringes were baked in an oven for at least $12 \mathrm{hr}$ at $45^{\circ} \mathrm{C}$ prior to use. Bioassays were conducted using extracts of VOCs collected from undamaged cotton plants, and plants damaged by boll weevils, Neotropical brown stink bugs, or fall armyworms, 24 and $96 \mathrm{hr}$ after insect damage was initiated. For the bioassays, extracts from the 24 and $96 \mathrm{hr}$ collections were concentrated to $100 \mu \mathrm{l}$ by nitrogen, and an aliquot of $5 \mu \mathrm{l}$ (equivalent to the volatiles released by one plant in $\sim 1 \mathrm{hr}$ ) were applied to filter paper $\left(1 \mathrm{~cm}^{2}\right)$. The solvent was allowed to evaporate for $1 \mathrm{~min}$ at ambient temperature prior to testing. The responses of male and female boll weevils were tested in the following combinations: VOCs from undamaged cotton plants (UD) vs. hexane $(N=30)$; VOCs from UD plants vs. VOCs from boll weevil-damaged plants (BWD; $N=60$ ); VOCs from UD plants vs. VOCs from Neotropical brown stink bug-damaged plants (BSBD; $N=$ 60 ); VOCs from UD plants vs. VOCs from fall armywormdamaged plants (FAWD; $N=60$ ), for both vegetative and reproductive cotton stages. We also tested VOC collections from BWD plants at the vegetative stage vs. VOC collections from BWD plants at the reproductive stage $(N=60)$. To certify that the air-entrainment extracts used in bioassays did not have aggregation pheromone, extracts were analyzed by gas chromatography/mass spectrometry (GC/MS) in the selected ion monitoring mode, monitoring $\mathrm{m} / \mathrm{z} 154,121$, 79 , and 68. Only extracts in which none of the four ions were detected were used in the bioassays. To test whether a combination of cotton plant VOCs and boll weevil aggregation pheromone was more effective at attracting conspecifics, the response of $A$. grandis $(N=60)$ to VOCs of BWD plants at the reproductive stage + aggregation pheromone vs. aggregation pheromone alone was tested. We also tested the effect of the aggregation pheromone alone vs. air $(N=$ 60 ). Weevils were starved for $24 \mathrm{hr}$ before assay and without access to water. All bioassays were carried out between 10:00 and 16:00 hr.

\section{Volatile Collections}

Gossypium hirsutum plants, at the vegetative or reproductive stages, were randomly assigned to UD, mechanicallydamaged (MD) or herbivore-damaged treatments. There were three herbivore-damaged treatments, in which cotton plants received (i) 2 males adults of $A$. grandis (BWD), (ii) 2 adults of E. heros (BSBD), or (iii) 2 3rd instars of $S$. frugiperda (FAWD). To encourage immediate feeding after being placed on the plants, insects were starved for $24 \mathrm{hr}$ prior to experiments. For the MD treatment, 3 leaves of cotton plants were wounded once with a hole punch. Plants were placed individually in cylindrical glass chambers (internal volume 101 ), as described by Michereff et al. (2011). The plastic pots and soil were covered by aluminum foil, in order to reduce collection of VOCs from these sources. Ten independent chambers were run simultaneously, enabling simultaneous VOC collections from all treatments. VOCs were collected for $24 \mathrm{hr}$, over 4 consecutive days $(N=$ 8 replicates for each treatment in both cotton phenological stages). A glass tube, containing $60 \mathrm{mg}$ of Super Q (80-100 mesh, Alltech, PA, USA), was connected via PTFE tubing to a vacuum pump at a flow of $0.61 . \mathrm{min}^{-1}$; the air entrance was connected to a flow of charcoal-filtered air $\left(1.01 . \mathrm{min}^{-1}\right)$ creating a positive pressure, 'push-pull' system. The trapped volatiles were eluted from the adsorbent with $500 \mu \mathrm{l}$ of $n$ - 
hexane, concentrated to $100 \mu$ by a nitrogen flow, and stored at $-20{ }^{\circ} \mathrm{C}$ until use. Fifty microliters of each extract was used for bioassays and the other $50 \mu$ used for chemical analyses [GC with flame ionization detection (FID) and $\mathrm{GC} / \mathrm{MS}]$.

\section{Chemical Analysis}

Extracts of VOCs were analyzed by GC (Agilent 7890, DB5 column, $60 \mathrm{~m} \times 0.32 \mathrm{~mm}$ ID, $1.0 \mu \mathrm{m}$ film, Supelco, Bellefonte, PA, USA), with the column oven programmed at $50{ }^{\circ} \mathrm{C}$ for 2 min., then to $180{ }^{\circ} \mathrm{C}$ at $5{ }^{\circ} \mathrm{C} \cdot \mathrm{min}^{-1}$, held for $0.1 \mathrm{~min}$, followed by an increase of $10^{\circ} \mathrm{C} \cdot \mathrm{min}^{-1}$ to $250{ }^{\circ} \mathrm{C}$ (held for $20 \mathrm{~min}$ ). The FID was at $270{ }^{\circ} \mathrm{C}$. For the GC analyses, hexadecanolide was added as an internal standard (IS), at $0.02 \mu \mathrm{g} \cdot \mathrm{ml}^{-1}$. One microliter of each sample was injected splitlessly, with helium as carrier gas. Data were collected with EZChrom Elite software. For compound identification, VOCs were analyzed on an Agilent 5975C quadrupole mass spectrometer, equipped with a DB-5 column $(30 \times 0.25 \mathrm{~mm}$ ID, $0.25 \mu \mathrm{m}$ film, Supelco, Bellefonte, PA, USA), a splitless injector, and helium as carrier gas. Ionization was electron impact $(70 \mathrm{eV}$, source temperature $200{ }^{\circ} \mathrm{C}$ ). Data were collected with ChemStation software. Identifications were made by comparison of spectra with library databases (NIST, 2008) or published spectra, use of retention indices (RIs; published at Pherobase 2011 and NIST Chemistry Web Book web sites), and by confirmation with authentic standards, when available.

\section{Statistical Analysis}

Data of the first choice of boll weevils were analyzed by a Chi-square test (5\% significance). Residence times of the weevils in each arm of the olfactometer were subjected to paired $t$ tests or Wilcoxon's matched-pairs tests when data did not match a normal distribution. As the volatile collections were carried out on the same cotton plants at several sampling times (24, 48, 72, and $96 \mathrm{hr}$ ), a repeated measures Generalized Linear Model (GLM) was used. Therefore, the total amounts of released VOCs from each treatment over time were compared using GLM, and Deviance Analyses with gamma distribution and inverse as link function. When the analyses showed significant effects of treatments, means were compared using contrast analyses. The change in chemical profile of damaged and undamaged cotton plants over time was assessed using Principal Response Curves (PRC) analysis. This multivariate technique allows the assessment of repeated measurements over time, focusing on the proportion of variance explained by treatments and time, compared to the control (UD). The PRC analysis was applied separately for each cotton plant phenological stage. In each set of analyses, the significance was determined by
Monte Carlo permutation test. All analyses were performed using the statistical program R 2.14.0 (R Development Core Team, 2009).

\section{Chemicals}

Super Q (80-100 mesh) was purchased from Alltech (PA, USA). Hexane for HPLC ( $\geq 97 \%$ and redistilled), $\alpha$-pinene (98\%), $\alpha$-camphene (90\%), benzothiazole (96\%), $\beta$ pinene (99\%), myrcene (90\%), (Z)-3-hexenyl acetate (98\%), (E)-3-hexenyl butyrate (98\%), (E)-ocimene (90\%), benzaldehyde (99\%), indole (98.5\%), methyl salicylate (99\%), $\alpha$-copaene (90\%), and alloaromadendrene ( $90 \%$ ) were purchased from Sigma Aldrich (Steinheim, Germany). Linalool, $\alpha$-humulene (96\%), (E)-caryophyllene $(80 \%)$, and limonene $(97 \%)$ were purchased from TCIAmerica (Portland, OR, USA). Geranylacetone (mixture of isomers) $(96 \%)$ and $c i s$-jasmone $(80 \%)$ were purchased from TCI (Tokyo, Japan). (E)-4,8-Dimethylnona-1,3,7-triene (DMNT) and (E,E)-4,8,12-trimethyltrideca-1,3,7,11-tetraene (TMTT) were synthesized from geraniol and $(E, E)$-farnesol, respectively (Leopold, 1990).

\section{Results}

\section{Olfactometer Assays}

In the Y-tube olfactometer, male $A$. grandis preferred VOCs released by cotton plants at the vegetative stage that had been damaged by conspecifics, for either $24\left(\chi^{2}=5.4, d f=1\right.$, $P=0.02)$ or $96 \mathrm{hr}\left(\chi^{2}=11.26, d f=1, P<0.001\right)$, compared to VOCs from the UD control. However, males showed no preference for VOCs released by cotton plants damaged by other insects compared to VOCs from UD plants (Fig. 1a). Female $A$. grandis showed the same response pattern, preferring VOCs collected from plants damaged by conspecifics, at both $24 \mathrm{hr}\left(\chi^{2}=4.26, d f=1, P=0.03\right)$ and $96 \mathrm{hr}$ $\left(\chi^{2}=21.6, d f=1, P<0.001\right)$, over those from UD controls; they also showed no preference for VOCs collected from cotton plants damaged by the other herbivores over those from UD plants (Fig. 1b). Male and female $A$. grandis spent more time in the olfactometer arm containing VOCs from cotton plants damaged by $A$. grandis, at either $24 \mathrm{hr}$ (paired $t$ test for males $t=2.415, d f=1, P=0.019$; for females $t=$ 3.715, $d f=1, P<0.001$ ) or $96 \mathrm{hr}$ (paired $t$ test for males $t=$ 2.405, $d f=1, P=0.008$; for females $t=3.802, d f=1, P<$ 0.001 ) compared to the olfactometer arm containing VOCs from UD plants.

The same pattern was observed when A. grandis adults were presented with VOCs from cotton plants at the reproductive stage. Male $A$. grandis preferred VOCs from plants damaged by $A$. grandis at $24 \mathrm{hr}\left(\chi^{2}=15, d f=1, P<0.001\right)$ or 
Fig. 1 First choice of male (a-c) and female (b-d) boll weevils, Anthonomus grandis, in a Y-tube olfactometer to extract of volatiles from cotton plants submitted to different damage treatments, or hexane only, vs. extract of volatiles from undamaged plants (control). $\mathbf{a}$ and $\mathbf{b}$ are of plants in the vegetative stage, and $\mathbf{c}$ and $\mathbf{d}$ are of plants in the reproductive stage. BWD-boll weevil-damaged plants, BSBD - Neotropical brown stink bug-damaged plants, FAWD-fall armywormdamaged plants. Volatiles were collected from plants for $24 \mathrm{hr}$, at both 24 and $96 \mathrm{hr}$ after treatment was started. Asterisks indicate differences ( $\chi^{2}$ test; $P<0.05)$ in boll weevils responses between pairs of treatments. Numbers in brackets are the number of insects that did not respond to either treatment

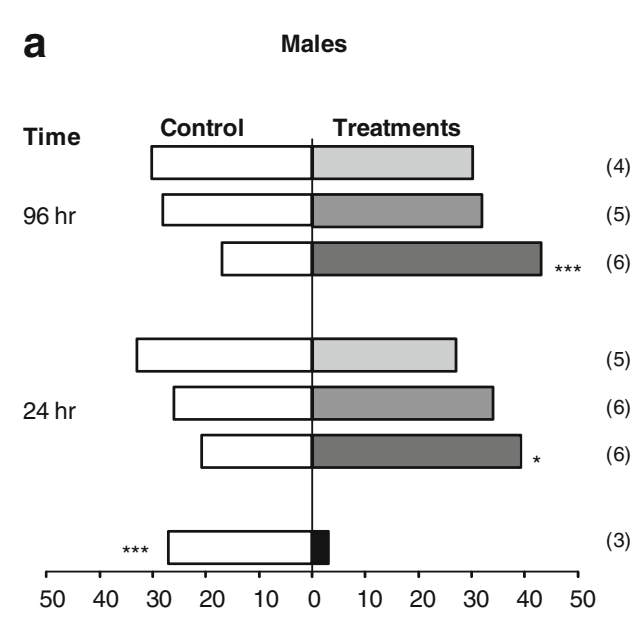

b Females

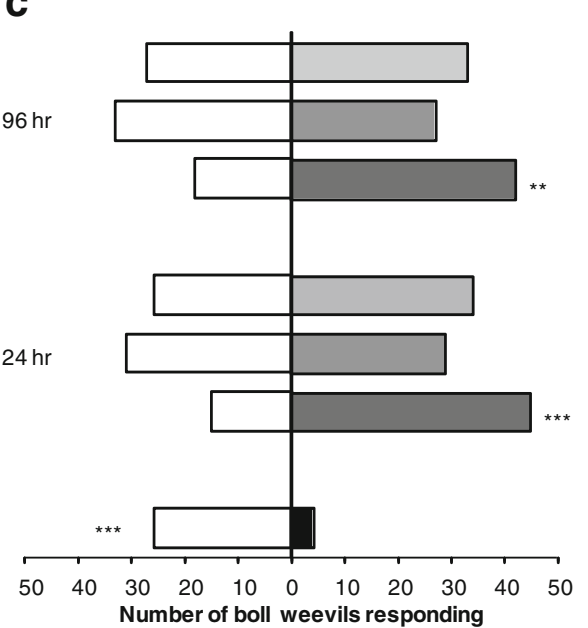

(4)

(5)

(6)

(5)

(6)

(6)

(3)

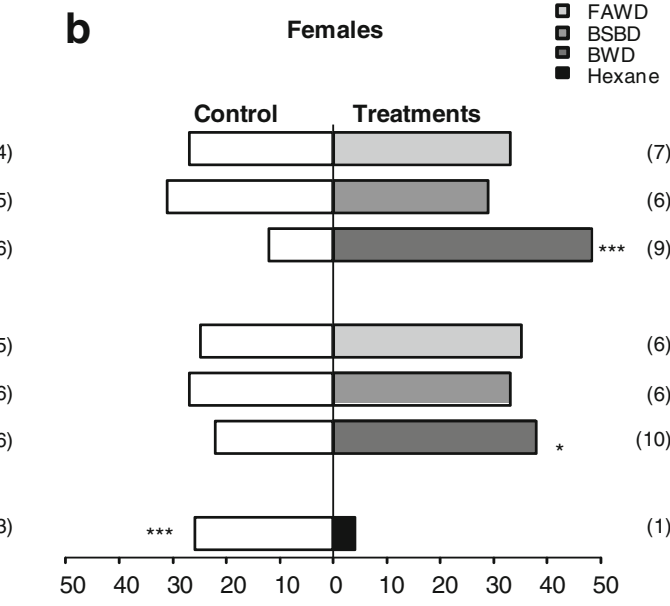

d

(7)

(7)

(11)

(10)

(9)

(3)

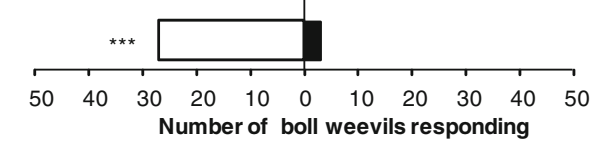

(10)
$96 \mathrm{hr}\left(\chi^{2}=9.6, d f=1, P=0.002\right)$, compared to VOCs emitted by UD cotton plants (Fig. 1c), and female $A$. grandis also preferred cotton VOCs emitted by plants damaged by conspecifics at $24 \mathrm{hr}\left(\chi^{2}=5.4, d f=1, P=0.02\right)$ and $96 \mathrm{hr}\left(\chi^{2}=\right.$ 9.6, $d f=1, P=0.002$ ), compared to VOCs emitted by UD plants (Fig. 1d). Both male and female A. grandis showed no preference for VOCs from either of the heterospecific-damaged cotton plants over UD controls. Only male boll weevils spent more time in the olfactometer arm containing VOCs from BWD plants, compared to the time spent in the arm containing VOCs from UD cotton plants (paired $t$ test $t=2.155, d f=1, P=$ 0.035 , and $t=2.535, d f=1, P=0.012$ for $24 \mathrm{hr}$ and $96 \mathrm{hr}$, respectively). The residence time for female boll weevils did not differ between treatments (paired $t$ test, $P>0.05$ ).

Since adult boll weevils preferred VOCs from cotton plants, at both vegetative and reproductive stages, damaged by conspecifics, we evaluated preference for odors from the two phenological stages. Both males and females were attracted to volatiles emitted by BWD plants at the reproductive stage over VOCs emitted by BWD plants at the vegetative stage, at both $24 \mathrm{hr}$ (males, $\chi^{2}=5.4, d f=1, P=0.02$; females, $\chi^{2}=9.6, d f=1, P<0.002$ ) and $96 \mathrm{hr}$ (males, $\chi^{2}=8.06, d f=1$, $P=0.004$; females, $\chi^{2}=6.66, d f=1, P<0.001$ ) (Fig. 2a). Similar results were obtained for residence time: male and female boll weevils spent more time in the arm containing VOCs of BWD plants at the reproductive stage at $24 \mathrm{hr}$ (males, Wilcoxon $W=-580, d f=1, P=0.033$; females, $W=-676, d f=$ $1, P=0.013$ ) or $96 \mathrm{hr}$ (males, $W=-700, d f=1, P=0.001$; females, $W=-660, d f=1, P=0.015$ ), compared to the VOCs emitted by corresponding BWD plants at the vegetative stage (Fig. 2b).

Male and female $A$. grandis preferred aggregation pheromone to clean air (male, $\chi^{2}=13.07, d f=1, P<0.001$; female, $\left.\chi^{2}=8.06, d f=1, P<0.001\right)$. The same pattern was observed for residence time (male, $t=2.584, d f=1, P=0.012$; female, $t=$ $2.137, d f=1, P=0.036)$. A combination of $A$. grandis aggregation pheromone with VOCs from BWD plants at the reproductive stage, at $24 \mathrm{hr}$ (male, $\chi^{2}=17.06, d f=1, P<0.001$; female, $\chi^{2}=6.66, d f=1, P=0.009$ ) or $96 \mathrm{hr}$ (male, $\chi^{2}=$ 13.03, $d f=1, P<0.001$; female, $\left.\chi^{2}=9.6, d f=1, P=0.002\right)$, was preferred by both male and female boll weevils compared to aggregation pheromone alone (Fig. 3a). Weevils also spent 


\section{a}

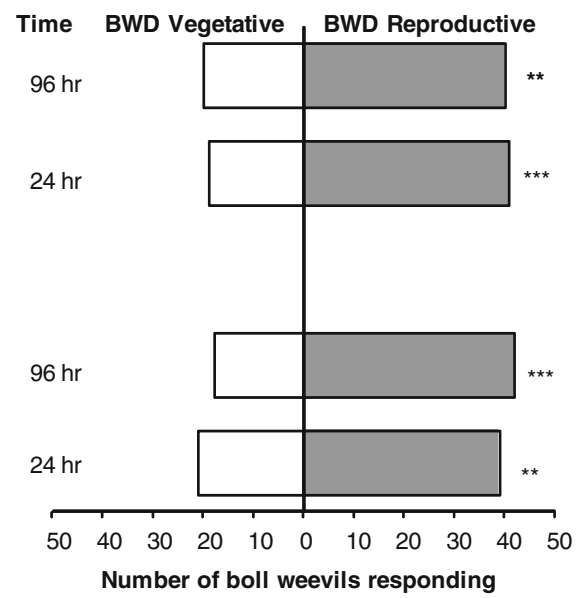

Fig. 2 First choices (a) and residence times (b) of male and female boll weevils, Anthonomus grandis, in a Y-tube olfactometer to extracts of volatiles from boll weevil-damaged (BWD) cotton plants at vegetative vs. reproductive phenological stages. Volatiles were collected from plants for

more time in the arm of the olfactometer containing the VOCs and pheromone mixture for damaged plants at $24 \mathrm{hr}$ (male, Wilcoxon $W=-760, d f=1, P=0.004$; female, $W=-557$, $d f=1, P=0.041)$ and $96 \mathrm{hr}$ (male, $W=-749, d f=1, P=$ 0.006 ; female $W=-690.0, d f=1, P=0.011$ ), compared to response the arm containing the aggregation pheromone alone (Fig. 3b).

\section{Volatile Analysis}

Chemical analysis of selected extracts of VOC collections from cotton plants revealed no qualitative differences among treatments. Compounds identified by GC/MS, using RI comparison

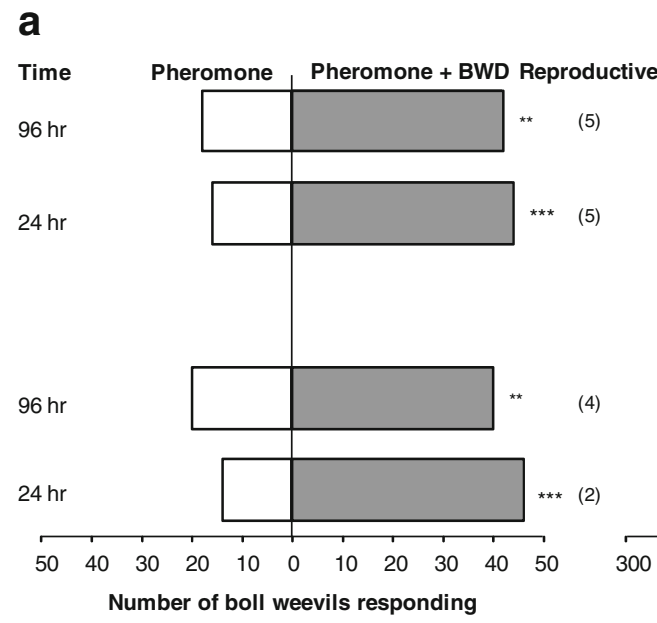

Fig. 3 First choices (a) and residence times (b) of male and females boll weevils, Anthonomus grandis, in a Y-tube olfactometer to extracts of volatiles from boll weevil aggregation pheromone versus aggregation pheromone + boll weevil-damaged (BWD) cotton plants at the reproductive stage. Volatiles were collected from plants for $24 \mathrm{hr}$, at

\section{b}

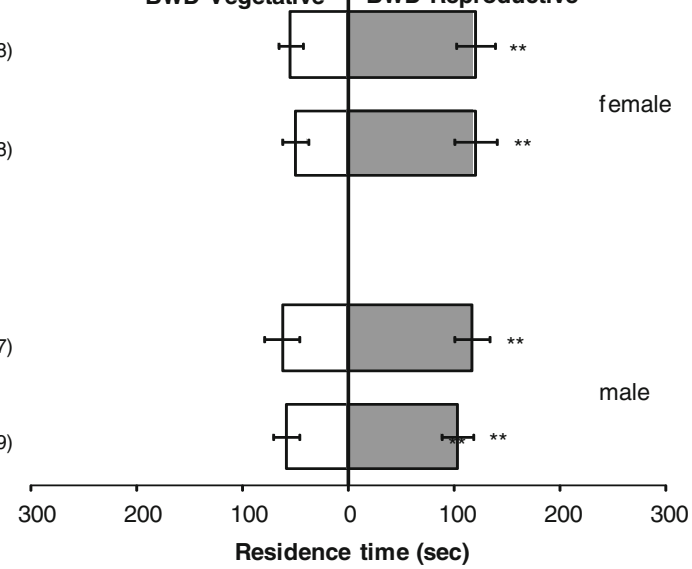

$24 \mathrm{hr}$, at both 24 and $96 \mathrm{hr}$ after treatment was started. Asterisks indicate differences $(P<0.05)$ between pairs of treatments (first choice by $\chi^{2}$ tests, and residence time by Wilcoxon's matched-pairs tests). Numbers in brackets are the number of insects that did not respond to either treatment

with authentic standards, included $\alpha$-pinene (RI=941), $\alpha$ camphene $(\mathrm{RI}=957)$, benzaldehyde $(\mathrm{RI}=966), \beta$-pinene $(\mathrm{RI}=984)$, myrcene $(\mathrm{RI}=993),(Z)-3$-hexenyl acetate $(\mathrm{RI}=$ 1010), limonene $(\mathrm{RI}=1036),(E)$-ocimene $(\mathrm{RI}=1053)$, linalool $(\mathrm{RI}=1104),(E)-4,8$-dimethylnona-1,3,7-triene (DMNT) $(\mathrm{RI}=$ 1119), (E)-3-hexenyl butyrate ( $\mathrm{RI}=1187)$, methyl salicylate $(\mathrm{RI}=1209)$, benzothiazole $(\mathrm{RI}=1236)$, indole $(\mathrm{RI}=1295), \alpha-$ copaene $(\mathrm{RI}=1389)$, cis-jasmone $(\mathrm{RI}=1416),(E)$-caryophyllene $(\mathrm{RI}=1437), \alpha$-guaine $(\mathrm{RI}=1452)$, geranylacetone $(\mathrm{RI}=$ 1466), $\alpha$-humulene $(R I=1472)$, alloaromadendrene $(R I=$ $1478), \alpha$-selinene $(R I=1504), \delta$-guaiane $(R I=1522), \delta$ cadinene $(\mathrm{RI}=1539)$, and $(E, E)-4,8,12$-trimethyltrideca1,3,7,11-tetraene (TMTT) (RI=1585). $\alpha$-Guaine, $\alpha$-selinene,

b

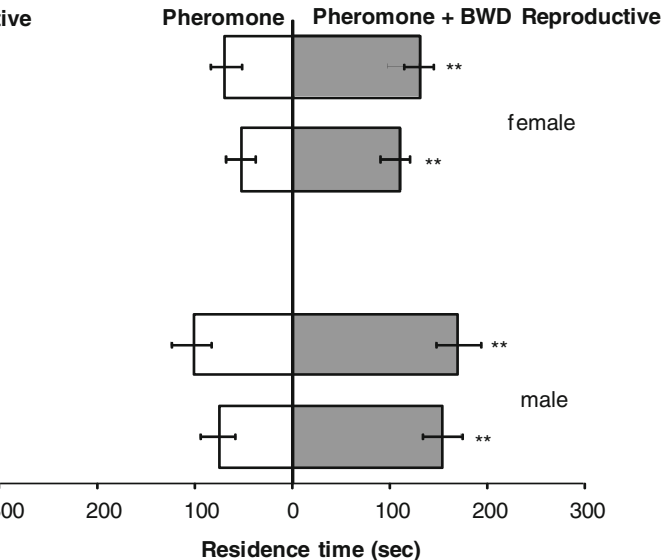

both 24 and $96 \mathrm{hr}$ after treatment was started. Asterisks indicate differences $(P<0.05)$ between pairs of treatments (first choices by $\chi^{2}$ tests and residence times by Wilcoxon's matched-pairs tests). Numbers in brackets are the number of insects that did not respond to either treatment 
$\delta$-guaiane, and $\delta$-cadinene were tentatively identified by comparisons of spectra and RIs, as no authentic standards were available. The total amount of VOCs produced by cotton plants differed among plants at the vegetative stage (ANODEV $\chi^{2}=$ 46.671, $d f=4, P<0.001$ ) and at the reproductive stage (ANODEV $\left.\chi^{2}=51.651, d f=4, P<0.001\right)$, and also in sampling time (ANODEV $\chi^{2}=15.384, d f=4, P<0.001$ ). For both phenological stages, the greatest amount of VOCs released occurred when plants were damaged by herbivores (Fig. 4a,b).

PRC analysis evaluated whether the VOCs released by herbivore-damaged plants was different from that of UD plants, and also identified the main compounds responsible for any differentiation. Cotton plants submitted to different treatments showed variability over time and among treatments (Fig. 5). For vegetative cotton plants, $27.10 \%$ of the total variance in the blend of released VOCs was explained by sampling time and $9.20 \%$ by induction treatment. The variance exhibited in the first PRC axis was significant (Monte Carlo permutation test $F=35.487, P=0.005$ ), and explained $74.41 \%$ of the variation in the blend composition due to interaction between sampling times and induction treatments. For reproductive cotton plants,
$47.67 \%$ of the total variance was explained by sampling times, $7.24 \%$ by induction treatment, and $54.50 \%$ by the interaction between sampling time and induction treatment; the variation in this PRC axis was also significant $(F=11.51, P=0.038)$. The volatile blend released by BWD and FAWD plants differed from that of UD plants, at both phenological stages (Fig. 5). The profiles of VOCs from MD and BSBD plants did not differentiate along time from the profile of control UD plants (Fig. 5). Compounds with effect values higher than $|0.5|$ contributed to the overall VOC blend response, and the greater this value, the higher their influence on the curve obtained in the plot; i.e., these compounds were deemed responsible for separating treatments. Thus, $\alpha$-pinene, $\beta$ pinene, myrcene, $(Z)$-3-hexenyl acetate, $(E)$-ocimene, linalool, DMNT, TMTT, $\alpha$-copaene, and geranylacetone (effect values $>|1.5|$ ) were the main compounds that contributed to the divergence between BWD and FAWD plants from UD plants (Fig. 5).

The total amount of monoterpenes released at the vegetative stage was different for BWD and FAWD plants from $48 \mathrm{hr}$ onward (ANODEV $\chi^{2}=40.301, d f=4, P<0.001$ )
Fig. 4 Amounts (mean \pm SEM) of total volatiles (a and $\mathbf{b}$ ), monoterpenes (c and $\mathbf{d}$ ), homoterpenes (e and $\mathbf{f}$ ), and sesquiterpenes ( $\mathbf{g}$ and $\mathbf{h})$ from undamaged cotton plants (UD), boll weevil-damaged plants (BWD), Neotropical brown stink bug-damaged plants (BSBD), fall armywormdamage plants (FAWD) and mechanically damaged plants (MD). $\mathbf{a}, \mathbf{c}, \mathbf{e}$, and $\mathbf{g}$ are from collections of cotton plants in the vegetative stage, while $\mathbf{b}, \mathbf{d}$, $\mathbf{f}$, and $\mathbf{h}$ are from collections of plants in the reproductive stage. Means with the same letter within a given time that the plants were sampled $(24$, 48,72 , or $96 \mathrm{hr}$ after treatment was started) are not different $(P>0.05)$, by ANODEV and mean comparisons by contrast analyses
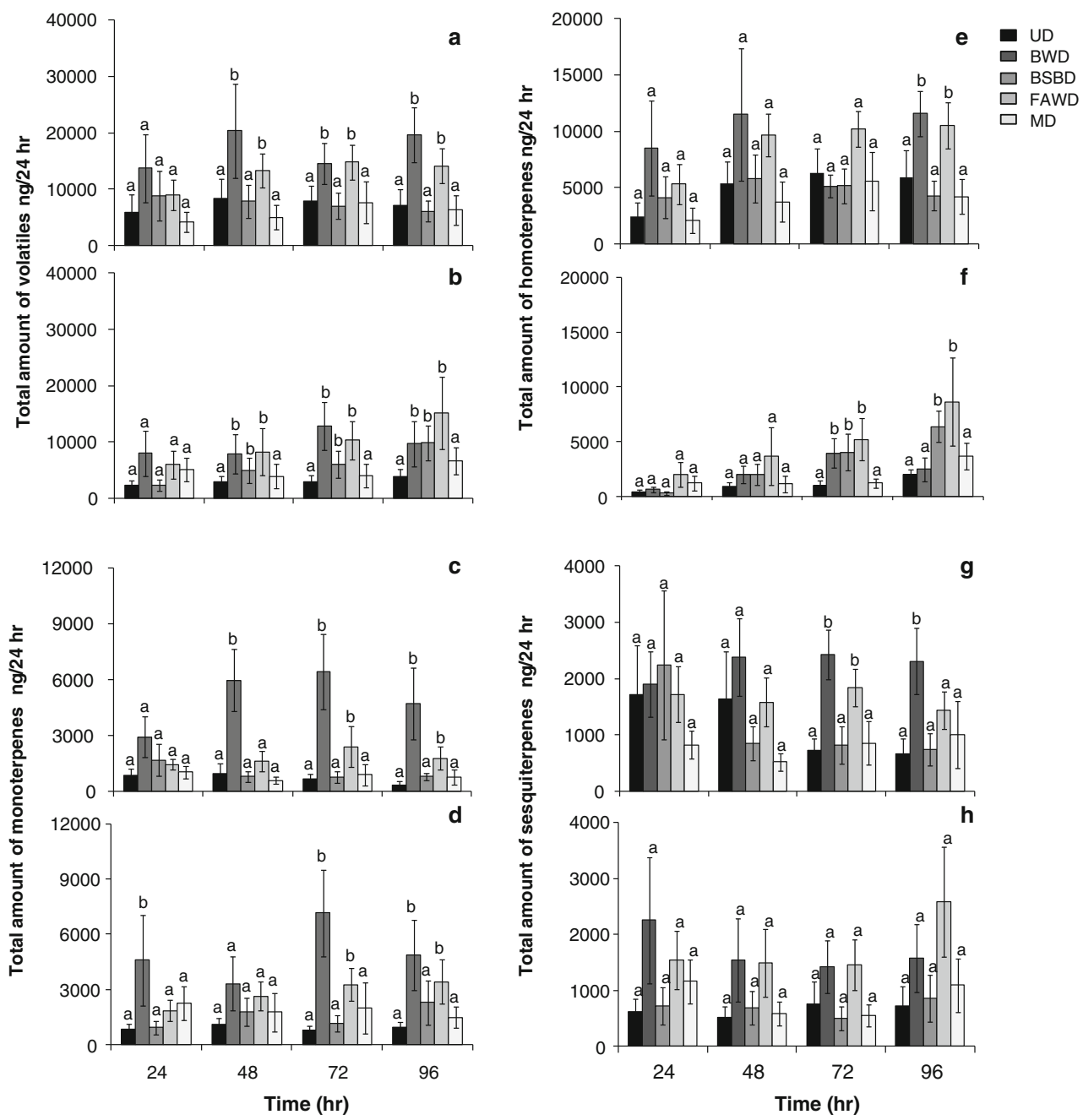
Fig. 5 Principal Response Curves (PRC) analyses of volatile blends released by vegetative (a) and reproductive (b) cotton plants on 4 days of sampling. The lines represent the response patterns of cotton plants to different treatments over time. $P$-values indicate significance of the PRC diagram over all sampling times, based on Monte Carlo permutation tests. Both cotton phenological stages displayed a significant part of the treatment variance (Monte Carlo permutation test, $P<0.05$ ), indicating that there was a significant induction treatment effect on the volatile blend released. UD - undamaged plants, BWD - boll weevil-damaged plants, BSBD-Neotropical brown stink bug-damaged plants, FAWD - fall armyworm-damaged plants, and $\mathrm{MD}$ - mechanically damaged plants. †Tentatively identified compounds a

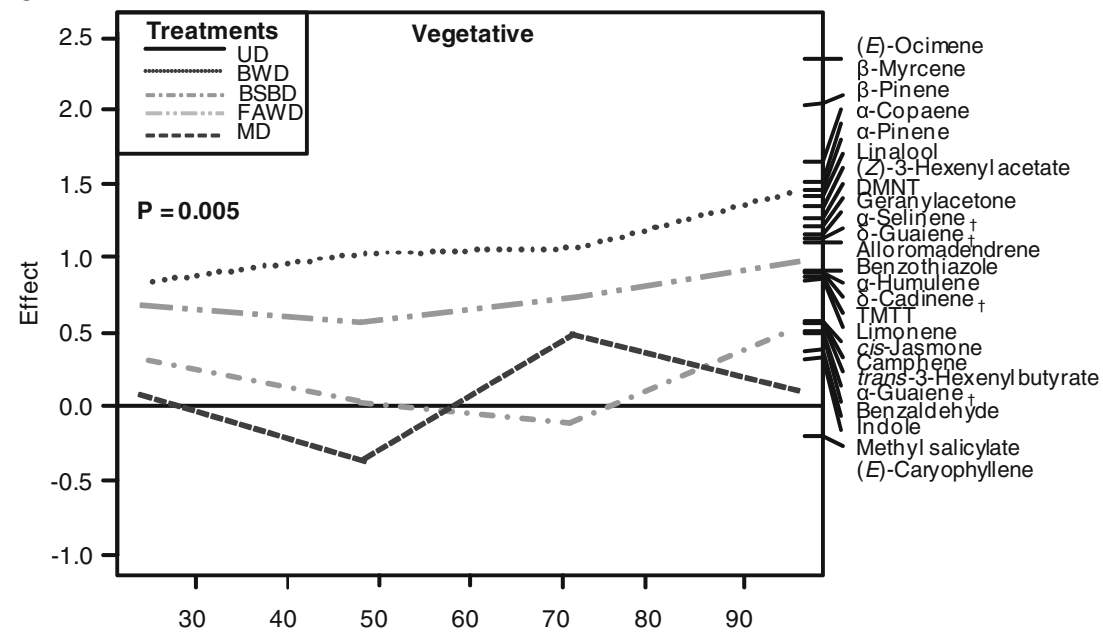

b

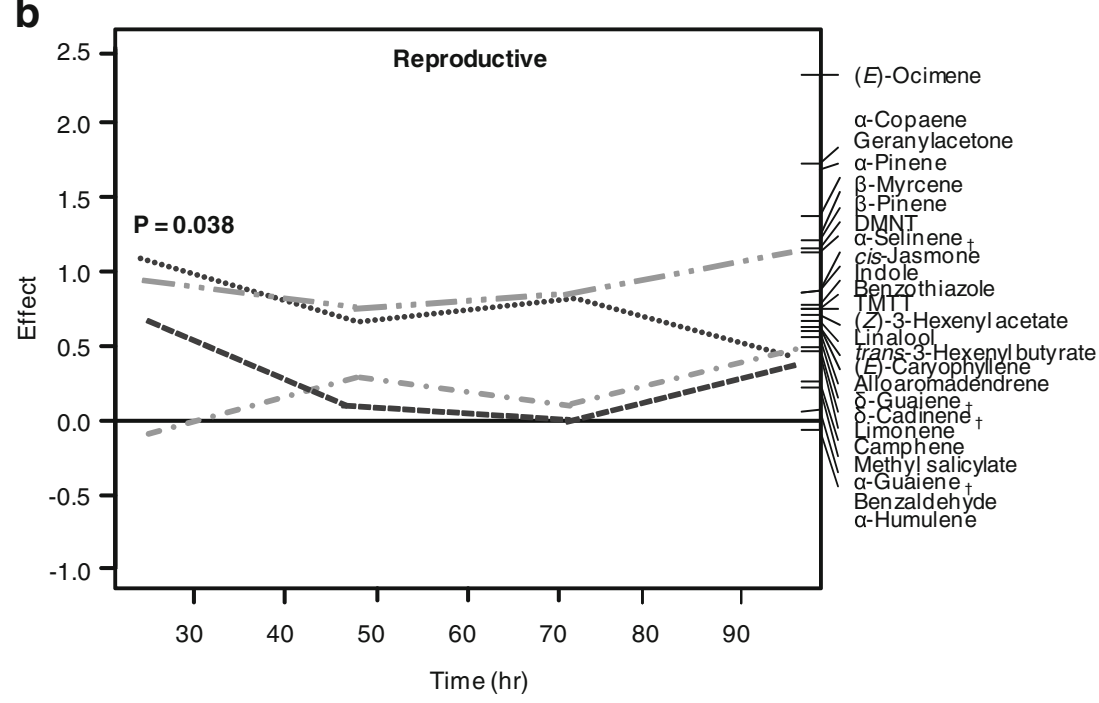

compared to other treatments (Fig. 4c). Similar results were obtained for reproductive stage plants (ANODEV $\chi^{2}=$ 25.796, $d f=4, P<0.001$ ) (Fig. $4 d$ ). (E)-Ocimene had the highest effect $(>|2.0|)$ on PRC analysis, when comparing among different treatments (Fig. 5). BWD plants at the vegetative and reproductive stages released a mean of $1158.8 \pm 258.2 \mathrm{ng} / 24 \mathrm{hr}$ and $1406 \pm 319.6 \mathrm{ng} / 24 \mathrm{hr}$, respectively, of $(E)$-ocimene across the 4 days, whereas UD plants at the vegetative and reproductive stages released $92.2 \pm$ $24.5 \mathrm{ng} / 24 \mathrm{hr}$ and $68.5 \pm 15.5 \mathrm{ng} / 24 \mathrm{hr}$, respectively, of $(E)$ ocimene. FAWD plants released $261.8 \pm 70.8 \mathrm{ng} / 24 \mathrm{hr}$ and $513.3 \pm 112.4 \mathrm{ng} / 24 \mathrm{hr}$ of $(E)$-ocimene, and BSBD plants $162.2 \pm 27.9 \mathrm{ng} / 24 \mathrm{hr}$ and $233.3 \pm 63.5 \mathrm{ng} / 24 \mathrm{hr}$, at the vegetative and reproductive stages, respectively. Furthermore, the total amounts of monoterpenes emitted by plants at the vegetative and reproductive stages were similar (ANODEV $\chi^{2}=0.252, d f=1, P=0.61$ ). Homoterpene (DMNT and TMTT) production was higher at the vegetative stage than at the reproductive stage (ANODEV $\chi^{2}=8.404, d f=1, P=$
0.003). At the vegetative stage, BWD and FAWD plants released higher amounts of DMNT and TMTT, only at $96 \mathrm{hr}$, compared to UD, MD, and BSBD plants (ANODEV $\chi^{2}=$ 12.714, $d f=4, P=0.012$ ) (Fig. 4e). At the reproductive stage, herbivore-damaged plants also released more DMNT and TMTT; FAWD and BSBD plants released higher amounts of DMNT and TMTT only at $96 \mathrm{hr}$ (ANODEV $\chi^{2}=16.255$, $d f=4, P=0.003$ ) (Fig. 4f). The total amount of aromatic (methyl salicylate, indole, benzothiazole, and benzaldehyde) (ANODEV $\chi^{2}=0.024, d f=1, P>0.05$ ), and green leaf volatile [(Z)-3-hexenyl acetate], compounds (ANODEV $\chi^{2}=$ $0.027, d f=1, P>0.05$ ) released were not different among treatments and across time (data not shown). The total amount of sesquiterpenes released differed between BWD and FAWD plants, only at the vegetative stage at $72 \mathrm{hr}$ (ANODEV $\chi^{2}=21.487, d f=4, P<0.001$; Fig. $4 \mathrm{~g}, \mathrm{~h}$ ). There were no differences (ANODEV $\chi^{2}=0.0598, d f=1, P=0.43$ ) in the amounts released between the reproductive and vegetative stages. 


\section{Discussion}

McKibben et al. (1977) established that adult $A$. grandis are attracted to constitutive volatiles released by cotton plants. Our study corroborated that work and explored the influence of plant phenological stage and infestation status in mediating this response. The Y-tube olfactometer assays demonstrated that $A$. grandis discriminate between volatiles released from cotton plants damaged by conspecifics and those released from undamaged cotton plants, but cannot discriminate between volatiles from cotton plants damaged by other herbivores (Neotropical brown stink bug and fall armyworm) and those emitted by undamaged plants. According to Bolter et al. (1997), biology may determine whether insect herbivores are attracted or repelled by volatiles from plants infested by conspecifics. Biological life-history attributes that may affect response include whether or not the herbivore exhibits aggregation behavior, as do boll weevils, whether or not the herbivore has natural enemies that might also be attracted to volatiles of infested plants, whether or not the herbivore has an efficient defense against natural enemies, and the specificity of the herbivore to the plant. The boll weevil has few natural enemies and, generally, under natural conditions (i.e., without mass releases of natural enemies), natural enemies do not represent a significant pressure on boll weevil populations (Nunes and Fernandes, 2000). Furthermore, A. grandis females lay eggs inside cotton reproductive structures (Showler, 2004), protecting eggs from natural enemies and adverse weather conditions. Anthonomus grandis adults use induced plant volatiles to find cotton plants and, because of this insect's high specificity to cotton plants, these volatiles probably provide a relatively safe mode for finding the plant.

Attraction of $A$. grandis to conspecific-damaged cotton plants appears to be linked to increased production of certain volatiles, which affects the ratio of individual compounds in the blend (Moraes et al., 2009; Bruce et al., 2010; Michereff et al., 2011), rather than production of qualitative new compounds. Damage by $A$. grandis induced greater production of volatiles by cotton plants than did damage by other herbivores we tested. Thus, the volatiles induced by herbivory may provide information about the presence of potential competitors on the host plant (Rochat et al., 2000; Yang et al., 2004), as well as enhancing $A$. grandis locating conspecifics for reproduction (Loughrin et al., 1996; Bernasconi et al., 1998). The latter is supported by our demonstration that boll weevils preferred the combination of aggregation pheromone plus volatiles from damaged, reproductive stage cotton plants, over aggregation pheromone alone.

In the Y-tube assays, we demonstrated that $A$. grandis preferred volatiles from cotton plants damaged at the reproductive stage over volatiles from cotton plants damaged at the vegetative stage. The total amounts of monoterpenes, GLVs, and aromatic compounds did not differ between $A$. grandis- damaged plants at the two stages. By contrast, levels of the homoterpenes DMNT and TMTT differed between the two stages, with release of these compounds greater when the vegetative stage was damaged. Both stages showed an increase in release of these compounds over time of damage. Release of the monoterpene $(E)$-ocimene did not differ between the plant phenological stages; however, this compound was released in greater amounts by plants damaged by $A$. grandis than by undamaged plants. As A. grandis primarily feed and oviposit solely on cotton reproductive structures, greater attraction to volatiles from the reproductive stage of the plant is expected. The preference of herbivores to certain plant phenological stages is well known (e.g., Kalinova et al. 2000; Szendrei et al., 2009; Addesso et al., 2011).

Male $A$. grandis that feed on cotton reproductive structures start production and release of aggregation pheromone that facilitates the arrival of other weevils. Previous studies showed that $(E)$-2-hexen-1-ol and $\beta$-bisabolol, paired with aggregation pheromone, increased attraction of adult boll weevils (Dickens, 1985, 1989; Dickens et al., 1990). Our results showed an increase in $A$. grandis response to aggregation pheromone when cotton volatiles were added. However, we did not find either of $(E)$-2-hexen-1-ol or $\beta$-bisabolol in the volatiles released by the cotton variety we used. Thus, other compounds must be responsible for the attraction of A. grandis to the cotton plants used in our study.

Our findings are consistent with those of other studies that have identified VOCs emitted by cotton (McCall et al., 1994; Loughrin et al., 1995; Paré and Tumlinson, 1998; Röse et al., 1998; Rodriguez-Saona et al., 2003; Hegde et al., 2011; Moraes et al., 2011). Our chemical analyses revealed that herbivore feeding caused increases in the total emission of volatile compounds, as reported previously (Paré and Tumlinson, 1996; Röse et al., 1996), with the type of feeding damage also affecting production. Chewing insects cause severe damage to plant tissues and are likely to induce stronger reactions in plants than will feeding by sucking herbivores, such as the Neotropical brown stinkbug. Low rates of volatile compounds released by cotton plants upon damage by sucking insects have been reported (Turlings et al., 1998; Rodriguez-Saona et al., 2003; Hegde et al., 2011). Damage by A. grandis resulted in differences in volatile production, compared to other treatments, $48 \mathrm{hr}$ after the start of damage, although adult $A$. grandis started to respond to cotton volatiles at only $24 \mathrm{hr}$ after the start of damage. According to our PRC analyses, $\alpha$-pinene, $\beta$ pinene, myrcene, $(Z)$-3-hexenyl acetate, $(E)$-ocimene, DMNT, $\alpha$-copaene, and TMTT contributed most to the separation profile observed, and thus may be involved in attracting $A$. grandis to cotton. Subsequent studies will use electrophysiological assays to identity the actual compounds responsible for attraction of $A$. grandis to cotton plants damaged at the reproductive stage. Such studies will allow 
the development of ecologically friendly trapping systems for monitoring and management of $A$. grandis.

Acknowledgments We thank Isabella Grisi for helping with laboratory rearing of the insects. We also thank the Post-Graduate Ecology Program of the University of Brasília (UnB) for use of their facility. This work received financial support from the Coordination of Superior Level Staff Improving's (CAPES) through a grant to Diego M Magalhães, and from the International Foundation for Science (IFS), Federal District Research Foundation (FAP-DF) and the Brazilian Corporation of Agricultural Research (EMBRAPA).

\section{References}

Addesso, K. M. and McAuslane, H. J. 2009. Pepper weevil attraction to volatiles from host and nonhost plants. Environ. Entomol. $38: 216-224$

Addesso, K. M., McAuslane, H. J., and Alborn, H. T. 2011. Attraction of pepper weevil to volatiles from damaged pepper plants. Entomol. Exp. App. 138:1-11.

Beltrão, N. E. M. and Azevedo, D. M. P. 2008. pp. 12-17, O agronegócio do algodão no Brasil. Embrapa Informação Tecnológica, Brasília.

Bernasconi, M. L., Turlings, T. C. J., Ambrosetti, L., Bassetti, P., and DoRN, S. 1998. Herbivore-induced emissions of maize volatiles repel the corn leaf aphid, Rhopalosiphum maidis. Entomol Exp. App. 87:133-142.

Bichão, H., BorG-KARLSON, A. K., ARAúJo, J., and Mustaparta, H. 2005. Five types of olfactory receptor neurons in the strawberry blossom weevil Anthonomus rubi: selective responses to inducible host plants volatiles. Chem. Senses 30:153-170.

Bolter, C. J., Dicke, M., Van-LoOn, J. J. A., Visser, J. H., and Posthumus, M. A. 1997. Attraction of Colorado potato beetle to herbivore-damaged plants during herbivory and after its termination. J. Chem. Ecol. 23:1003-1023.

Borges, M., Laumann, R. A., Silva, C. A. S., Moraes, M. C. B., SANTOS, H. M., and TiBÚRCIO, D. T. 2006. pp. 18, Metodologias de criação e manejo de colônias de percevejos da soja (Hemiptera-Pentatomidae) para estudos de comportamento e ecologia química. Documento $\mathrm{N}^{\mathrm{o}}$ 182. Editora Embrapa, Brasília, Brasil

Borges, M., Millar, J. G., Laumann, R. A., and Moraes, M. C. B. 2007. A male-produced sex pheromone from the neotropical redbanded stink bug, Piezodorus guildinii (W.). J. Chem. Ecol. $33: 1235-1248$

Bruce, T. J. A., Midega, C. A. O., Birkett, M. A., Pickett, J. A., and KHAN, Z. R. 2010. Is quality more important than quantity? Insect behavioural responses to changes in a volatile blend after stemborer oviposition on an African grass. Biol. Lett. 6:314-317.

DICKENS, J. C. 1984. Olfaction in the boll weevil, Anthonomus grandis Boh. (Coleoptera: Curculionidae): eletroantennogram studies. $J$. Chem. Ecol. 10:1759-1785.

DiCKENS, J. C. 1985. Orientation of boll weevil, Anthonomus grandis Boh. (Coleoptera: Curculionidae), to pheromone and volatile host compound in the laboratory. J. Chem. Ecol. 12:91-98.

DiCKENS, J. C. 1989. Green leaf volatiles enhance aggregation pheromone of boll weevil, Anthonomus grandis. Entomol. Exp. App. 52:191-203

Dickens, J. C., JANG, E. B., Light, D. M., and Alford, A. R. 1990. Enhancement of insect pheromone responses by green leaf volatiles. Naturwissenschaften 77:29-31.
HARE, J. D. 2011. Ecological role of volatiles produced by plants in response to damage by herbivorous insects. Annu. Rev. Entomol. $56: 161-180$

Hegde, M., Oliveira, J. N., Costa, J. G., Bleicher, E., Santana, A. E. G., Bruce, T. J. A., Caulfield, J., Dewhirst, S. Y., Woodcock, C. M., Pickett, J. A., and Birkett, M. A. 2011. Identification of semiochemical released by cotton, Gossypium hirsutum, upon infestation by the cotton aphid, Aphis gossypii. J. Chem. Ecol. 37:741-750.

Kalberer, N. M., Turlings, T. C. J., and Rahier, M. 2001. Attraction of leaf beetle (Oreina cacaliae) to damaged host plants. J. Chem. Ecol. 27:647-661.

Kalinova, B., Stransky, K., Harmatha, J., Ctvrtecka, R., and ZD'AREK, J. 2000. Can chemical cues from blossom buds influence cultivar preference in the apple blossom weevil (Anthonomus pomorum)? Entomol. Exp. Appl. 95:47-52.

LEOPOLD, E. J. 1990. Selective hydroboration of a 1, 3, 7-triene: homogeraniol. Org. Synth. 64:164-171.

Loughrin, J. H., Manukian, A., Heath, R. R., and Tumlinson, J. H. 1995. Volatiles emitted by different cotton varieties damaged by feeding beet armyworm larvae. J. Chem. Ecol. 21:1217-1222.

Loughrin, J. H., PotTer, D. A., HAMilton-Kemp, T. R., and Byers, M. E. 1996. Role of feeding-induced plant volatiles in aggregative behavior of the Japanese beetle (Coleoptera: Scarabaeidae). Environ. Entomol. 25:1188-1191.

McCall, P. J., Turlings, T. C. J., Loughrin, J., ProveauX, A. T., and TumLinson, J. H. 1994. Herbivore-induced volatile emissions from cotton (Gossypium hirsutum L.) seedlings. J. Chem. Ecol. 20:3039-3049.

McKibien, G. H., Mitchell, E. B., Scott, W. P., and Hedin, P. A. 1977. Boll weevils are attracted to volatile oils from cotton plants. Environ. Entomol. 6:804-806.

Meiners, T., Hacker, N. K., ANDERson, P., and HilKer, M. 2005. Response of the elm leaf beetle to host plants induced by oviposition and feeding: the infestation rate matters. Entomol. Exp. Appl. 115:171-177.

Michereff, M. F. F., Laumann, R. A., Borges, M., Micherefr Filho, M., Diniz, I. R., Farias-Neto, A. L., and Moraes, M. C. B. 2011. Volatiles mediating plant-herbivory-natural enemy interaction in resistant and susceptible soybean cultivars. $J$. Chem. Ecol. 37:273-285.

Moraes, M. C. B., Laumann, R. A., Sujin, E. R., Pires, C. S. S., Borges, M., and Millar, J. G. 2005. Sex attractant pheromone from the neotropical red-shouldered stink bug, Thyanta perditor (F.). J. Chem. Ecol. 31:1415-1427.

Moraes, M. C. B., Laumann, R. A., Pareja, M., Sereno, F. T. P. S., MicherefF, M. F. F., Birkett, M. A., Pickett, J. A., and BORGES, M. 2009. Attraction of the stink bug egg parasitoid Telenomus podisi to defence signals from soybean activated by treatment with cis-jasmone. Entomol. Exp. Appl. 131:178188.

Moraes, M. C. B., Laumann, R. A., Aquino, M. F. S., Paula, D. P., and Borges, M. 2011. Effect of Bt genetic engineering on indirect defense in cotton via a tritrophic interaction. Transgenic Res. 20:99-107.

NIST. 2011. Software NIST/EPA/NIH Mass Spectral Library 2011.

NIST. 2008. Software NIST/EPA/NIH Mass Spectral Library 2008.

NunES, J. C. S. and FERNANDES, P. M. 2000. Parasitismo do bicudo do algodoeiro (Anthonomus grandis) em botões florais do algodoeiro, no município de Goiânia-GO. Pesqui. Agropecu. Trop. 30:13-15.

PARÉ, P. W. and Tumlinson, J. H. 1998. Cotton volatiles synthesized and released distal to the site of insect damage. Phytochemistry 47:521-526.

PARÉ, P. W. and Tumlinson, J. H. 1996. Volatile signals in response to herbivore feeding. Fla. Entomol. 79:93-103. 
Pherobase. 2011. Database of pheromone and other semiochemicals. $<$ http://www.pherobase.com/database/kovats/kovats-index.php>.

R DeVElopment Core TeAm. 2009. A language and environment for statistical computing. R Foundation for Statistical Computing, Vienna, Austria.

Ribeiro, P. A., Sujit, E. R., Diniz, I. R., Medeiros, M. A., SalgadoLabouriau, M. L., Branco, M. C., Pires, C. S. S., and Fontes, E. M. G. 2010. alternative food sources and overwintering feeding behavior of the boll weevil, Anthonomus grandis Boehman (Coleoptera: Curculionidae) under the tropical conditions of Central Brazil. Neotropical Entomol. 39:28-34.

Rochat, D., Meillour, P. N., Esteban-Duran, J. R., Malosse, C., Perthuis, B., Morin, J. P., and Descoins, C. 2000. Identification of pheromone synergists in the American palm weevil, Rhynchophorus palmarum, and attraction of related Dynamis borassi. J. Chem. Ecol. 26:155-187.

Rodriguez-Saona, C., Crafts-Brandner, S. J., and CAÑas, L. A. 2003. Volatile emissions triggered by multiple herbivore damage: beet armyworm and whitefly feeding on cotton plants. J. Chem. Ecol. 29:2539-2550.

Röse, U. R. S., Manukian, A., Heath, R. R., and TumLinson, J. H. 1996. Volatile semiochemicals released from undamaged cotton leaves (a systemic response of living plants to caterpillar damage). Plant Physiol. 111:487-495.

RÖSE, U. R. S., LEWIS, W. J., and TuMLINSON, J. H. 1998. Specificity of systemically released cotton volatiles as attractants for specialist and generalist parasitoid wasps. J. Chem. Ecol. 24:303-319.

RUMMEL, D. R. and CURRY, G. L. 1986. Dinâmica populacional e níveis de dano econômico, pp. 201-220, in S. Barbosa, M. J. Lukefarh, and R. B. Sobrinho (eds.), O Bicudo do Algodoeiro, Vol. 4. Departamento de Difusão Tecnológica Documentos, Embrapa.
Schmidt, F. G. V., Monnerat, R. G., Borges, M., and Carvalho, R. S. 2001. pp. 20, Metodologia de Criação de Insetos para Avaliação de Agentes Entomapatogênicos. Circular Técnica $\mathrm{N}^{\mathrm{o}}$ 11. Ed. Embrapa, Brasília, Brasil.

SHOWLER, A. T. 2004. Influence of cotton fruit stages as food sources on boll weevil (Coleoptera:Curculionidae) fecundity and oviposition. J. Econ. Entomol. 97:1330-1334.

STAMPS, J. and KRISHNAN, V. V. 2005. Nonintuitive cue use in habitat selection. Ecology 86:2860-2867.

iSzendrei, Z., MAlo, E., Stelinski, L., and RodrigueZ-SAONA, C. 2009. Response of cranberry weevil (Coleoptera: Curculionidae) to host plant volatiles. Entomol. Soc. Am. 38:861-869.

Tumlinson, J. H., Hardee, D. D., Gueldner, R. C., Thompson, A. C., Hedin, P. A., and Minyard, J. P. 1969. Sex pheromone produced by the male boll weevil: isolation, identification, and synthesis. Science 166:1010-1012.

Turlings, T. C. J., Tumlinson, J. H., and Lewis, W. J. 1993. An elicitor in caterpillar oral secretion that induces corn seedlings to emit chemical signals attractive to parasitic wasps. J. Chem. Ecol. 19:411-425.

Turlings, T. C. J., Bernasconi, M., Bertossa, R., Bigler, F., CALOZ, G., and DoRN, S. 1998. The induction of volatile emissions in maize by three herbivore species with different feeding habits: possible consequences for their natural enemies. Biol. Control. 11:122-129.

White, J. R. and RUMMEL, D. 1978. Re-emergence profile of overwintered boll weevils an entry into cotton. Environ. Entomol. 7:714.

YAnG, Z., Bengtsson, M., and WitzGall, P. 2004. Host plant volatiles synergize response to sex pheromone in codling moth, Cydia pomonella. J. Chem. Ecol. 30:619-629. 